\title{
Investigating Decreased Rates of Nulliparous Cesarean Deliveries during the COVID-19 Pandemic
}

\author{
Colleen M. Sinnott, MD ${ }^{1}$ Taylor S. Freret, MD, EdM ${ }^{1}$ \\ Sarah E. Little, MD, MPH ${ }^{3}$ \\ ${ }^{1}$ Department of Obstetrics and Gynecology, Brigham and Women's \\ Hospital, Boston, Massachusetts \\ 2 Department of Maternal Fetal Medicine, Massachusetts General \\ Hospital, Boston, Massachusetts \\ ${ }^{3}$ Department of Maternal Fetal Medicine, Brigham and Women's \\ Hospital, Boston, Massachusetts
}

\author{
Mark A. Clapp, MD, MPH ${ }^{2}$ Emily Reiff, MD ${ }^{3}$
}

Am J Perinatol 2021;38:1231-1235.
Address for correspondence Colleen Sinnott, MD, Department of Obstetrics and Gynecology, Brigham and Women's Hospital, 75 Francis Street, Boston, MA 02115 (e-mail: csinnott1@partners.org).

\begin{abstract}
Keywords

- COVID-19

- cesarean delivery prevention

- singleton deliveries

Objective Preventing the first cesarean delivery $(C D)$ is important as $C D$ rates continue to rise. During the novel coronavirus disease 2019 (COVID-19) pandemic, quality improvement metrics at our hospital identified lower rates of $C D$. We sought to investigate this change and identify factors that may have contributed to the decrease. Study Design We compared nulliparous singleton deliveries at a large academic hospital during the COVID-19 pandemic (April through July 2020 during a statewide "stay-at-home" order) to those in the same months 1 year prior to the pandemic (April through July 2019). The primary outcome, mode of delivery, was obtained from the electronic medical record system, along with indication for CD.

Results The cohort included 1,913 deliveries: 892 in 2019 and 1,021 in 2020. Patient characteristics (age, body mass index, race, ethnicity, and insurance type) did not differ between the groups. Median gestational age at delivery was the same in both groups. The CD rate decreased significantly during the COVID-19 pandemic compared with prior ( 28.9 vs. $33.6 \% ; p=0.03$ ). There was a significant increase in the rate of labor induction ( 45.7 vs. $40.6 \% ; p=0.02$ ), but no difference in the proportion of inductions that were elective ( 19.5 vs. $20.7 \%$; $p=0.66$ ). The rate of $C D$ in labor was unchanged ( 15.9 vs. $16.3 \% ; p=0.82$ ); however, more women attempted a trial of labor (87.0 vs. $82.6 \% ; p=0.01$ ). Thus, the proportion of $C D$ without a trial of labor decreased ( $25.1 \mathrm{vs.}$ $33.0 \% ; p=0.04)$.

Conclusion There was a statistically significant decrease in CD during the COVID-19 pandemic at our hospital, driven by a decrease in CD without a trial of labor. The increased rate of attempted trial of labor suggests the presence of patient-level factors that warrant further investigation as potential targets for decreasing CD rates. Additionally, in a diverse and medically complex population, increased rates of labor induction were not associated with increased rates of $C D$.
\end{abstract}

received

April 26, 2021

accepted

June 17, 2021

published online

July 19, 2021 (c) 2021. Thieme. All rights reserved.

Thieme Medical Publishers, Inc., 333 Seventh Avenue, 18th Floor, New York, NY 10001, USA
DOI https://doi.org/

10.1055/s-0041-1732449.

ISSN $0735-1631$. 
Key Points

- Primary CD rate fell during COVID-19 pandemic.

- Decrease was driven by more women attempting labor.

- Higher rate of induction without rise in $C D$ rate was found.

Cesarean delivery $(C D)$ rates have risen significantly in the United States over the past decades. ${ }^{1}$ While it is already established that cesarean deliveries are associated with higher maternal morbidity, newer literature have also suggested increased neonatal morbidity and financial consequences related to the rising rate of $\mathrm{CD} .^{2-4}$ As many women will opt for elective repeat cesarean after a primary $C D$, campaigns to prevent the primary $\mathrm{CD}$ have developed. ${ }^{5}$

Suggestions have included allowing for a longer second stage, implementing a CD "checklist" to avoid nonindicated cesarean sections or incorporating more "midwifery-style care," such as positional changes during labor and intermittent fetal heart auscultation. ${ }^{6-8}$ These interventions have met with varying levels of success, and preventing the primary CD remains a major focus of investigation.

On March 23, 2020, in response to the novel coronavirus disease 2019 (COVID-19) pandemic, a state-wide stay-athome order was issued. Additionally, hospital-wide policy changes occurred, including an increased emphasis on telemedicine and remote care in outpatient obstetric $(\mathrm{OB})$ clinics and limiting the number of support people for laboring women on labor and delivery.

During the time of hospital protocol changes, quality improvement data for our institution suggested a reduction in the rate of $\mathrm{CD}$ by several percentage points. Our primary objective was to quantify the reduction in the rate of $\mathrm{CD}$ associated with the COVID-19 pandemic and identify factors potentially related to this decrease. Identification of such factors could help inform counseling and management to reduce the $\mathrm{CD}$ rate, as well as associated maternal and neonatal morbidity and health care costs, in the long-term.

\section{Materials and Methods}

This was a retrospective cohort study comparing all nulliparous singleton deliveries at a single large academic hospital in Boston, MA, during the months of a state-wide stay-athome recommendation during the COVID-19 pandemic (April through July 2020) to those singleton deliveries at the same hospital and in the same months during the same time period 1 year prior in a pre-COVID era (April through July 2019). The same four months were chosen for both cohorts to account for any potential variation in delivery patterns and patient characteristics throughout the calendar year. The study was approved by the Partners Human Research Committee (protocol no.: 2020P001887).

All singleton deliveries occurring to nulliparous women were identified by review of the electronic medical record system. Data regarding these deliveries, including demographics and delivery type and indication for $\mathrm{CD}$ or induction of labor, were then obtained from the electronic medical record system. "Trial of labor" was defined as either spontaneous labor or induced labor.

CDs were grouped as occurring "during labor" or "not during labor." CD during labor included indications such as fetal intolerance of labor, failure to progress, worsening maternal status during labor, and failed operative delivery. $\mathrm{CD}$, not during labor, included indications such as malpresentation/breech, prior uterine surgery, maternal medical complication, fetal anomalies, and placenta or vasa previa. If the indication for $\mathrm{CD}$ was not listed in the electronic medical record, individual chart review was performed by the primary author (C.M.S.).

Additional chart review of operative reports, ultrasound imaging, and prenatal records was performed for all women in the "cesarean delivery without a trial of labor" group to determine whether these women met criteria for a trial of labor. For example, chart review was performed to assess whether external cephalic version was attempted prior to $C D$ for breech presentation. Similarly, operative notes were reviewed where available for women who underwent $C D$ for a history of prior uterine surgery to determine if future $\mathrm{CD}$ had been recommended. For any $\mathrm{CD}$ with an unclear contraindication to trial of labor, the chart was then separately reviewed by a second author for clarity (S.E.L.).

\section{Statistical Methods}

All data were analyzed in SAS 9.4 (Cary, NC). Binary outcomes were compared with Chi-squared or Fisher's exact testing, where appropriate. Continuous variables were compared with nonparametric methods using Wilcoxon's testing.

\section{Results}

There were 1,909 nulliparous singleton deliveries during the two cohorts of interest: 890 in April to July of 2019 and 1,019 in April to July of 2020. Patient characteristics including age, body mass index, race, ethnicity, and insurance type did not differ significantly between the groups. Median gestational age at delivery was the same in both groups (39.4 weeks, $p=0.12$, - Table 1 ).

During the COVID era, the CD rate was lower than in the pre-COVID era ( 28.8 vs. $33.5 \%, p=0.03$, - Table 2 ). There was no difference in the rate of $C D$ during labor (19.1 vs. $19.8 \%$, $p=0.72$ ); however, the rate of $\mathrm{CD}$ without trial of labor decreased (9.6 vs. $13.7 \%, p<0.01$ ). This appeared to be driven by an increase in the proportion of women attempting a trial of labor during the COVID-era (90.4 vs. $86.3 \%, p<0.01$ ). Additionally, the rate of labor induction increased (45.8 vs. $40.7 \%, p=0.02$ ). Of note, there was no difference in the rate of 
Table 1 Patient characteristics

\begin{tabular}{|c|c|c|c|}
\hline & \multicolumn{2}{|l|}{ Year } & \multirow[t]{3}{*}{$p$-Value } \\
\hline & 2019 & 2020 & \\
\hline & $(n=890)$ & $(n=1,019)$ & \\
\hline Age (IQR) in years & $31(29-34)$ & $32(29-34)$ & 0.51 \\
\hline $\mathrm{BMI}(\mathrm{IQR})$ in $\mathrm{kg} / \mathrm{m}^{2}$ & $\begin{array}{l}29.4 \\
(26.6-33.1)\end{array}$ & $\begin{array}{l}29.4 \\
(26.5-33.4)\end{array}$ & 0.96 \\
\hline \multicolumn{4}{|l|}{$\begin{array}{l}\text { Race } \\
n(\%)\end{array}$} \\
\hline White & $585(65.7)$ & $650(63.8)$ & \multirow[t]{4}{*}{0.62} \\
\hline Black & 85 (9.6) & $115(11.3)$ & \\
\hline Asian & $104(11.7)$ & $116(11.4)$ & \\
\hline Other/unknown ${ }^{a}$ & $116(13.0)$ & $138(13.5)$ & \\
\hline \multicolumn{4}{|l|}{$\begin{array}{l}\text { Ethnicity } \\
n(\%)\end{array}$} \\
\hline Hispanic & $119(13.4)$ & $127(12.5)$ & \multirow[t]{2}{*}{0.62} \\
\hline $\begin{array}{l}\text { Not Hispanic } \\
\text { Unknown }\end{array}$ & $\begin{array}{l}749(84.2) \\
22(2.5)\end{array}$ & $\begin{array}{l}855(83.9) \\
37(3.6)\end{array}$ & \\
\hline \multicolumn{4}{|l|}{$\begin{array}{l}\text { Insurance type } \\
n(\%)\end{array}$} \\
\hline Public & $113(12.7)$ & 119 (11.7) & 0.50 \\
\hline Private & & & \\
\hline
\end{tabular}

Abbreviations: BMI, body mass index; IQR, Interquartile range. Note: Data presented with IQR represents median value with associated IQR.

ather includes Native American, Pacific Islander, and patients who reported multiple races.

elective inductions of labor despite the increase in overall induction rate ( 19.5 vs. $20.7 \%, p=0.66$ ).

There was no change in the rate of operative delivery between the two cohorts (11.1 vs. $10.5 \%, p=0.66$ ).

Subgroup analysis of all individual indications for $\mathrm{CD}$ without trial of labor, including breech/malpresentation, placenta previa, prior uterine surgery, fetal anomaly, or maternal medical showed no difference between the two groups (-Table 3 ).
For these same indications, there was no difference in the proportion of women who underwent $\mathrm{CD}$ but who were candidates for trial of labor. Among women who had a CD for breech/malpresentation, there was no difference in the rates of attempted external cephalic version (ECV). In both cohorts, there were relatively low rates of primary $C D$ for maternal request ( - Table 4 ).

\section{Discussion}

Our study found that the $\mathrm{CD}$ rate decreased nearly $5 \%$ points at one institution during the COVID-19 pandemic; however, this decrease was driven entirely by a decrease in the rate of $\mathrm{CD}$ without a trial of labor. There was no change in the rate of $\mathrm{CD}$ after a trial of labor despite an increase in the rate of labor induction during the COVID-19 pandemic. Among CDs performed without a trial of labor, there was no change in the distribution of indication, nor was there any change in the

Table 3 Indications for cesarean delivery without trial of labor

\begin{tabular}{|c|c|c|c|}
\hline & $\begin{array}{l}2019 \\
(n=122) \\
n(\%)\end{array}$ & $\begin{array}{l}2020 \\
(n=98) \\
n(\%)\end{array}$ & $p$-Value \\
\hline Breech/malpresentation & $63(51.6)$ & 46 (41.9) & \multirow[t]{7}{*}{0.61} \\
\hline Previa (placenta or vasa) & $8(6.6)$ & $7(7.1)$ & \\
\hline Prior uterine surgery ${ }^{a}$ & $11(9.0)$ & $13(13.3)$ & \\
\hline Fetal anomaly & $10(8.2)$ & $5(5.1)$ & \\
\hline $\begin{array}{l}\text { Nonreassuring fetal } \\
\text { testingb }\end{array}$ & $4(3.3)$ & $4(4.1)$ & \\
\hline $\begin{array}{l}\text { Maternal medical } \\
\text { condition }\end{array}$ & 17 (13.9) & $10(10.2)$ & \\
\hline Elective & $9(7.4)$ & $13(13.3)$ & \\
\hline
\end{tabular}

${ }^{\mathrm{a} A l l}$ cases reviewed in this category were prior myomectomies.

${ }^{\mathrm{b}}$ This category included exclusively patients in whom nonreassuring fetal testing outside of labor was identified and the patient then proceeded directly to primary cesarean delivery.

\begin{tabular}{|llll|}
\hline Table 2 Delivery methods and trial of labor & & & \\
\hline & $\mathbf{2 0 1 9}(\boldsymbol{n}=\mathbf{8 9 0})$ & $\mathbf{2 0 2 0}(\boldsymbol{n}=\mathbf{1 , 0 1 9 )}$ & \\
& $\boldsymbol{n}(\%)$ & $\mathbf{n}$-Value & \\
Gestational age at delivery (IQR) in weeks & $39.43(38.3-40.1)$ & $39.4(38.4-40.3)$ & 0.12 \\
Trial of labor, all & $768(86.3)$ & $921(90.4)$ & $<0.01^{\mathrm{a}}$ \\
Cesarean delivery, all & $298(33.5)$ & $293(28.8)$ & $0.03^{\mathrm{b}}$ \\
Cesarean delivery, during labor & $176(19.8)$ & $195(19.1)$ & 0.72 \\
Cesarean delivery, without labor & $122(13.7)$ & $98(9.6)$ & $<0.01^{\mathrm{a}}$ \\
IOL total & $362(40.7)$ & $467(45.8)$ & $0.02^{\mathrm{b}}$ \\
Proportion of IOL elective & $20.7 \%$ & $19.5 \%$ & 0.66 \\
Operative vaginal delivery & $99(11.1)$ & $107(10.5)$ & 0.66 \\
\hline
\end{tabular}

Abbreviations: IOL, labor induction; IQR, interquartile range. ${ }^{\mathrm{a}} \mathrm{p}<0.05$. 


\begin{tabular}{|c|c|c|c|}
\hline & 2019 & 2020 & $p$-Value \\
\hline Breech, total & 63 & 46 & \\
\hline ECV attempted (\%) & $19(30.2)$ & $15(32.6)$ & 0.79 \\
\hline Placenta previa, total & 8 & 7 & \\
\hline Candidate for labor ${ }^{\mathrm{a}}(\%)$ & $2(2.5)$ & $1(14.5)$ & 0.60 \\
\hline $\begin{array}{l}\text { Prior uterine surgery, } \\
\text { total }\end{array}$ & 11 & 13 & \\
\hline Candidate for labor (\%) & $0(0)$ & $0(0 \%)$ & - \\
\hline $\begin{array}{l}\text { Maternal medical } \\
\text { condition, total }\end{array}$ & 17 & 10 & \\
\hline Candidate for labor (\%) & $6(35.3)$ & $3(30.0)$ & 0.78 \\
\hline Fetal abnormality, total & 10 & 5 & \\
\hline Candidate for labor & $2(20)$ & $0(0)$ & 0.28 \\
\hline $\begin{array}{l}\text { Nonreassuring fetal } \\
\text { testing, total } \\
\text { Candidate for labor (\%) }\end{array}$ & $\begin{array}{l}4 \\
0(0)\end{array}$ & $\begin{array}{l}4 \\
0(0)\end{array}$ & - \\
\hline $\begin{array}{l}\text { Elective, total } \\
\text { Candidate for labor (\%) }\end{array}$ & $\begin{array}{l}9 \\
9(100)\end{array}$ & $\begin{array}{l}13 \\
13(100)\end{array}$ & - \\
\hline $\begin{array}{l}\text { Any unlabored cesarean } \\
\text { delivery, total }\end{array}$ & 122 & 98 & \\
\hline Candidate for labor (\%) & 19 (15.6) & 17 (17.4) & 0.72 \\
\hline
\end{tabular}

Abbreviation: ECV, external cephalic version.

${ }^{a}$ Candidacy for labor determined by chart review of operative reports, ultrasound images, and other documentation for criteria including distance of placental edge to cervical os, extent of prior uterine surgery, and other characteristics.

proportion of women who may have otherwise been considered a candidate for labor.

We initially postulated that due to the COVID-19 pandemic, more mothers may have chosen the concrete certainty of an induction date rather than awaiting spontaneous labor, and that this increase in labor induction rate was directly tied to the falling $C D$ rate. In other words, it seemed a real world manifestation and perhaps even confirmation of the ARRIVE trial. ${ }^{9}$ Another theory was that due to the COVID-19 pandemic, OB providers, including nurses, physicians, and midwives, simply entered labor and delivery rooms with less frequency in an attempt to maintain as much social distancing as possible, and that perhaps this decrease in "interventional-ism" in labor resulted in the decreased CD rate. However, when specifics of the Cesarean deliveries were more carefully examined, these initial hypotheses do not seem to hold true.

When it became clear that the driving force behind the decrease in $C D$ rates was indeed among $C D$ without a trial of labor, we hypothesized that rates of nonindicated CD may have decreased during the COVID-19 pandemic due to more stringent restrictions on surgical procedures. However, this was ultimately not found to be the case, as despite review of these cases by at least one obstetrician, and in more complex cases two obstetricians, there were very few marginally indicated $C D$ cases identified in the prepandemic time peri- od. Attempts to avoid the primary CD in the 2019 cohort were admirable but did not support a theory of less-strict implementation of $\mathrm{CD}$ criteria prior to the COVID-19 pandemic.

At the conclusion of this analysis, it appears that there must be, as of yet, unrecognized factors at play, either related or unrelated to the COVID-19 pandemic, and likely patientdriven, as no changes in labor practices were identified. One potential explanation could be that women who required scheduled primary CDs and were otherwise healthy, uncomplicated patients may have sought care at smaller hospitals closer to home to avoid spending time in a large urban hospital during the COVID-19 pandemic; however, this seems an incomplete explanation as there were more total deliveries in the 2020 pandemic cohort as compared with the year prior. Further monitoring of the $\mathrm{CD}$ rate over the coming months at our institution will be critical to assess whether the decrease persists or whether the rate returns to the prepandemic mean.

Reassuringly, despite an increase in the rate of labor inductions, there was no change in the rate of $C D$ after trial of labor. In a population diverse in age, ethnicity, body mass index, and medical complexity, this is a reassuring validation of recent data, showing that induction of labor in a lowrisk population of nulliparous women is associated with lower rates of $\mathrm{CD} .^{9}$ Moreover, our study population's heterogeneity and varying levels of maternal medical risk adds to its generalizability, suggesting that induction of labor in higher risk populations is not associated with higher rates of $C D$.

\section{Limitations}

The major limitation of this study was the short time period used in the analysis. This was specifically chosen in an attempt to isolate the true impact of the COVID-19 pandemic, as after July 2020, while the pandemic persisted, it briefly lessened in severity in our area, leading to resumption of nearer normal hospital activity. However, as demonstrated in this investigation, studying large-scale metrics, such as $C D$ rates, would likely be more accurate over longer time periods to decrease the impact of variation around the mean. Additionally, our study was not powered to detect small differences in the individual indications for $C D$, limiting our conclusion.

\section{Conclusion}

Despite initially promising findings of a sharp decrease in primary CD during the COVID-19 pandemic, analysis ultimately demonstrated that this decrease was entirely driven by a decrease in $C D$ without trial of labor, although we could not isolate specific changes in indication. Encouragingly there was no change in the rate of $C D$ after trial of labor despite a marked rise in the rate of labor induction. In a population diverse in age, ethnicity, body mass index, and medical complexity, increased rates of labor induction are not associated with increased rates of $C D$. 
Note

Findings of this study were previously presented at the 41st Annual Pregnancy Meeting of the Society for Maternal Fetal Medicine, virtually, from January 25 to 30, 2021.

Funding

None.

\section{Conflict of Interest}

None declared.

\section{References}

1 Centers for Disease Control and Prevention. Cesarean delivery rate by state. Accessed April 18, 2021 at: https://www.cdc. gov/nchs/pressroom/sosmap/cesarean_births/cesareans.htm

2 Forde B, DeFranco EA. Association of prior cesarean delivery with early term delivery and neonatal morbidity. Obstet Gynecol 2020; 135(06):1367-1376

3 DeJoy SA, Bohl MG, Mahoney K, Blake C. Estimating the financial impact of reducing primary cesareans. J Midwifery Womens Health 2020;65(01):56-63
4 Creanga AA, Bateman BT, Butwick AJ, et al. Morbidity associated with cesarean delivery in the United States: is placenta accreta an increasingly important contributor? Am J Obstet Gynecol 2015; 213(03):384.e1-384.e11

5 Caughey AB, Cahill AG, Guise JM, Rouse DJ; American College of Obstetricians and Gynecologists (College) Society for MaternalFetal Medicine. Safe prevention of the primary cesarean delivery. Am J Obstet Gynecol 2014;210(03):179-193

6 Zipori Y, Grunwald O, Ginsberg Y, Beloosesky R, Weiner Z. The impact of extending the second stage of labor to prevent primary cesarean delivery on maternal and neonatal outcomes. Am J Obstet Gynecol 2019;220(02):191.e1-191.e7

7 Toumi M, Lesieur E, Haumonte J-B, Blanc J, D’ercole C, Bretelle F. Primary cesarean delivery rate: potential impact of a checklist. J Gynecol Obstet Hum Reprod 2018;47(09):419-424

8 Cox KJ, King TL. Preventing primary cesarean births: midwifery care. Clin Obstet Gynecol 2015;58(02):282-293

9 Grobman WA, Rice MM, Reddy UM, et al; Eunice Kennedy Shriver National Institute of Child Health and Human Development Maternal-Fetal Medicine Units Network. Labor induction versus expectant management in low-risk nulliparous women. N Engl J Med 2018;379(06):513-523 